Prepared under the joint sponsorship of the GOVERNMENT OF LIBERIA and the AGENCY FOR INTERNATIONAL DEVELOPMENT U.S. DEPARTMENT OF STATE

\title{
TOTAL-COUNT GAMMA RADIATION MAP OF THE ZWEDRU QUADRANGLE, LIBERIA \\ By
}

Cletus S. Wotorson and John C. Behrendt

FOLIO OF THE ZWEDRU QUADRANGLE, LIBERIA MAP I-777 C

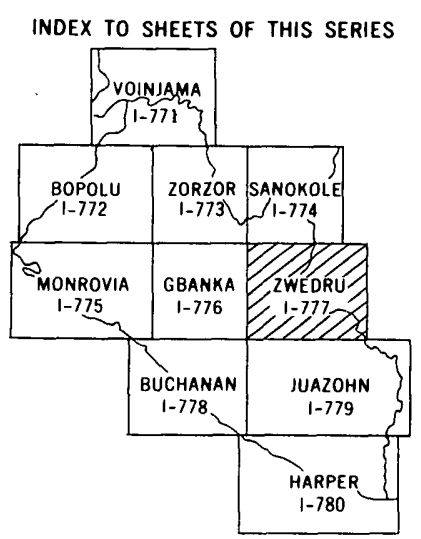

PUBLISHED BY THE U. S. GEOLOGICAL SURVEY RESTON, VA. 22092 1974 